\title{
Myostatin downregulates the expression of basic fibroblast growth factor gene in HeLa cells
}

\author{
Liu $\mathrm{HZ}^{1}$, Luo $\mathrm{P}^{2}$, Chen $\mathrm{SH}^{1}$, Shang $\mathrm{JH}^{3}$ \\ Modern Biochemistry Centre, Guangdong Ocean University, Zhanjiang, China. zj902030@163.com
}

\begin{abstract}
Basic fibroblast growth factor (bFGF or FGF-2), a potent tumorigenic cytokine, improves cells proliferation and angiogenesis in tumor and also plays vital roles in tumor growth, metastasis as well as prognosis. Screening and application of effective cytokines against bFGF tumorigenic activity would be helpful to oncologic therapy. Myostatin, a member of transforming growth factor $\beta$ superfamily, recently showed an antitumor activity and was reported to induce HeLa cells apoptosis through mitochondrion pathway. The above data raised our assumption that expression level of endogenous bFGF gene may be suppressed by exogenous myostatin in myostatin-treated HeLa cells. To test the hypothesis, myostatin was employed to stimulate HeLa cells and expressional level of endogenous bFGF gene in HeLa cells was detected with real-time RT-PCR and ELISA. Results of the suppressed expression level of bFGF gene in Hela cells implied that myostatin may be regarded as an effective cytokine against bFGF to treat certain cancers (Fig. 3, Ref. 26). Full Text in PDF www.elis.sk. Key words: myostatin, basic fibroblast growth factor, HeLa cells.
\end{abstract}

As a mitogen and differentiation factor for neuroectoderm- or mesoderm-derived cells, basic fibroblast growth factor (bFGF or FGF-2) has been demonstrated to be a multifunctional cytokine, especially its potent tumorigenic activity $(1,2)$. Background researches revealed that bFGF stimulated cells proliferation and angiogenesis in tumor and is involved in tumor growth, metastasis as well as prognosis through autocrine and paracrine manners, thus the cytokine has been regarded as a target molecule for curing cancers by concerned scientists. Based on these positive roles of bFGF on tumorigenesis, neutralizing antibodies against bFGF, employed to restrain cell growth and tumorigenesis in vivo and in vitro, have been demonstrated to inhibit the proliferation of human glioblastoma cells (3), HeLa cells (3), melanoma cells (4) and other tumor cells expressed bFGF and membrane FGF receptors in vitro through inducing cell apoptosis. In addition, Yang et al (5) discovered that overexpression of bFGF gene stimulated proliferation of HeLa cells, whereas overexpression of antisense bFGF gene inhibited proliferation of the cancer cells.

${ }^{1}$ Modern Biochemistry Centre, Guangdong Ocean University, Zhanjiang, China, ${ }^{2}$ College of Food Science \& Technology, Guangdong Ocean University, Zhanjiang, China, and ${ }^{3}$ Guangxi Key Laboratory of Buffalo Genetics, Reproduction and Breeding, Buffalo Research Institute, Chinese Academy of Agricultural Sciences, Nanning, China

Address for correspondence: Jianghua Shang, Guangxi Key Laboratory of Buffalo Genetics, Reproduction and Breeding, Buffalo Research Institute, Chinese Academy of Agricultural Sciences, Nanning 530001, China

Acknowledgements: The authors thank grants from Natural Science Foundation of Guangxi Zhuang Autonomous Region of China (0991011) and Natural Science Foundation of Guangdong Ocean University for financial support.
It is well known that myostatin, a member of the transforming growth factor beta superfamily, negatively regulates skeletal muscle mass (6). Deletion of myostatin induces muscle overgrowth while overexpression or systemic administration results in atrophy. Studies have demonstrated that myostatin inhibited the proliferation of myoblasts and satellite cells via multisignal pathways (7-9). Overexpression of antisense myostatin enhanced differentiation of rhabdomyosarcoma RD cells (10) and suppression of myostatin induced proliferation of rhabdomyosarcoma cells through a retinoblastoma-independent pathway (11), which implied myostatin was probably involved in regulating tumorigenesis of skeletal muscle. In addition, myostatin is also concerned with other tissue-derived tumors. Bian et al (12) observed that myostatin induced apoptosis of cervical cancer HeLa cells and human lung adenocarcinoma A549 cells through mitochondrion pathway. In view of these facts, it may well be that myostatin can be selected as a drug for curing tumor in clinical application.

Previously, we described that bFGF impaired the expression of myostatin gene in murine $\mathrm{C} 2 \mathrm{C} 12$ myoblasts (13) and extracellular signal-regulated kinase $1 / 2$ participated in the regulatory mechanism, which improved skeletal muscle development and regeneration (14). On the basal roles on tumor and the relationship of the two cytokines in myoblasts, we presume that there may be an interaction between bFGF and myostatin in tumor cells, and is interesting to know whether inhibition of expression of bFGF gene will be induced by myostatin in myostatin-treated tumor cells. To investigate this, in the present study, myostatin was employed to stimulate Hela cells and then mRNA and protein levels of endogenous bFGF were detected by real-time reverse transcriptionpolymerase chain reaction (RT-PCR) and indirect enzyme-linked immunosorbent assay (ELISA). 
471-475

\section{Materials and methods}

\section{Cell culture}

Cervical cancer HeLa cells were cultured in Dulbecco's modified Eagle's medium (DMEM) supplemented with $10 \%$ fetal bovine serum (FBS) at $37{ }^{\circ} \mathrm{C}$ with $5 \% \mathrm{CO}_{2}$ in a humidified atmosphere.

\section{Quantitative RT-PCR}

According to our previous work (13), total RNA was extracted and used to detect the mRNA levels of bFGF and glyceraldehydes 3-phosphate dehydrogenase (GAPDH) genes in HeLa cells, the relative abundances of the two genes were assessed by real-time RT-PCR. The quantitative RT-PCR was performed using SYBR GREEN PCR master mix on an ABI PRISM 7900 Sequence Detector System. Annealing temperatures and primer sequences of bFGF and GAPDH genes were shown as follows. For the bFGF gene, primers 5'-GACCCACACATCAAACTACAACTTC-3' and 5'-TCCATCTTCTTTCATAG CAAGGTAA-3', annealing temperature $58{ }^{\circ} \mathrm{C}$ and product size $99 \mathrm{bp}$; for the GAPDH gene, primers 5'-TGATGACATCAAGAAGGTGGTGAAG-3' and 5'-TCCTTGGAGGCC ATGTAGGCCAT-3', annealing terperature $62{ }^{\circ} \mathrm{C}$ and product size $240 \mathrm{bp}$, bFGF mRNA level was normalized with GAPDH mRNA level.

\section{Detection of bFGF protein content in cell culture medium}

In the light of our published paper (13), indirect ELISA was used to detect bFGF protein level in cell culture medium. The method was briefly described as follow. A 96-well flat-bottomed assay plate coated with monoclonal antibody against human bFGF at the concentration of $5 \mu \mathrm{g} / \mathrm{ml}$ was kept at $4{ }^{\circ} \mathrm{C}$ for $8 \mathrm{~h}$ and then washed three times with PBS containing $1 \%$ Tween-20 (PBST), $1 \%$ skim milk powder was added into plate wells followed by incubation for another $1 \mathrm{~h}$ at $37^{\circ} \mathrm{C}$ in a humidified atmosphere. Cell culture supernatant was added into washed plate and kept at $37^{\circ} \mathrm{C}$ for $2 \mathrm{~h}$. Plate was washed three times with PBST again, polyclonal antibody against bFGF was added into the washed wells and then incubated for $1 \mathrm{~h}$ at $37^{\circ} \mathrm{C}$. A secondary antibody labeled with horseradish peroxidase was added into the rewashed wells and incubated for $1 \mathrm{~h}$ at $37^{\circ} \mathrm{C}$. After washing plate, TMB was added into wells and kept for $10 \mathrm{~min}$ in dark conditions at room temperature for color development. The optical density values were read at the wavelength of $450 \mathrm{~nm}$.

\section{Western blotting analysis}

The western blotting assay procedure for $\beta$-actin protein in Hela cells was following. Cells in dishes were lysed at $4{ }^{\circ} \mathrm{C}$ in non-denaturing cell lysis buffer, the harvested lysate was denatured in protein sample buffer for $5 \mathrm{~min}$ in boiling water. Followed SDS-polyacrylamide gel electrophoresis (SDS-PAGE), protein was transferred to nitrocellulose membrane and then probed with antibodies. SuperSignal West Pico chemiluminesence detection system (Pierce, Rockford, USA) was employed to visualize the membrance. For western blotting analysis of bFGF protein secreted into cell culture supernatant, harvested cell culture supernatant was concentrated by nine times, denatured in protein sample buffer for $5 \mathrm{~min}$ in boiling water and subjected to SDS-PAGE. The following process was same as the detection procedure of $\beta$-actin. Content of bFGF protein was normalized with $\beta$-actin protein.

\section{Statistical analysis}

Statistical analysis was performed using the SPSS software and Student's $t$-test was used to determine significant differences between the groups. Significance was considered at $\mathrm{p}<0.05$ or $\mathrm{p}<0.01$.

\section{Results}

Ground on the opposite biological roles of bFGF and myostatin on HeLa cells and our published relationship between the two growth factors in murine $\mathrm{C} 2 \mathrm{C} 12$ myoblasts, we speculated
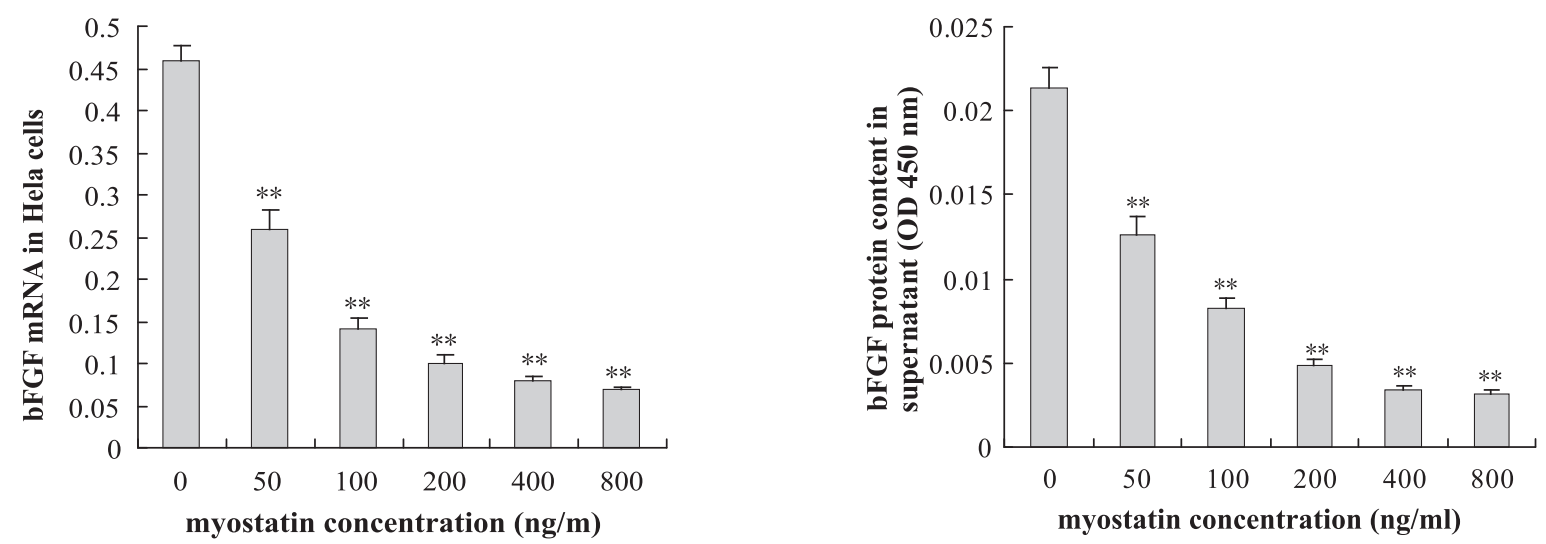

Fig. 1. Protein (right) and mRNA (left) levels of bFGF in HeLa cells suppressed by different doses of exogenous myostatin. The cultured Hela cells grown in DMEM with $0.5 \%$ FBS were stimulated by recombinant human myostatin at indicated concentrations respectively. Cells in part of culture dishes were treated by the fusion myostatin protein for $30 \mathrm{~min}$ and employed to extract total RNA contributing to detecting mRNA level of bFGF with real-time RT-PCR, the other cells were stimulated for $6 \mathrm{~h}$ and submitted to investigate bFGF protein content in supernatant with ELISA. Each value was expressed as the mean \pm standard deviation. ** $\mathbf{p}<0.01$, vs untreated cells by myostatin. 

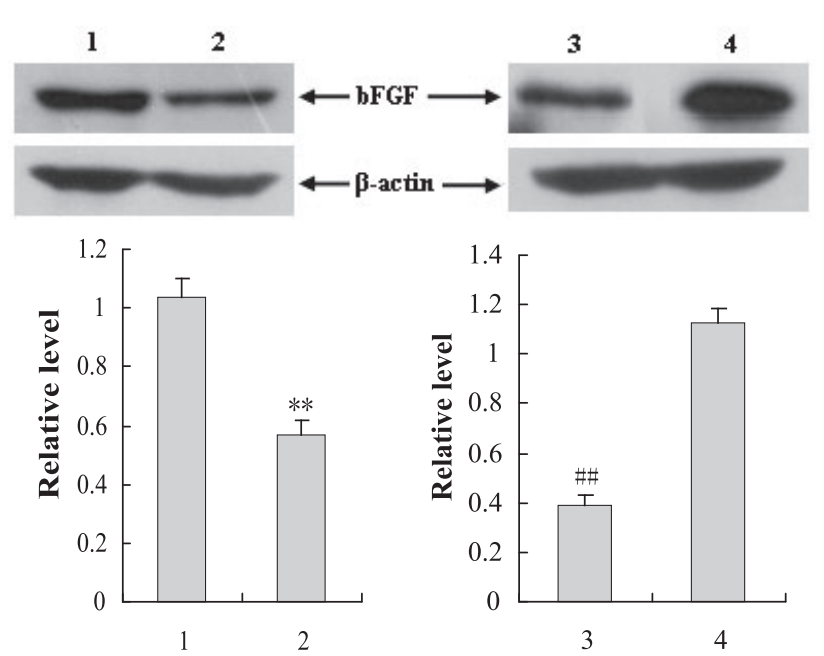

Fig. 2. Western blotting assay for bFGF protein content in supernatant secreted by myostatin-stimulated HeLa cells. Bar 1 and bar 2 respectively represented bFGF protein levels in the supernatants from the culture dishes treated with myostatin at the concentration of $\mathbf{0}$ and $50 \mathrm{ng} / \mathrm{ml}$ for $6 \mathrm{~h}$. Bar 3 or bar 4 represented bFGF protein level in the supernatants from the culture dishes treated with myostatin $(50 \mathrm{ng} / /$ $\mathrm{ml}$ ) for $12 \mathrm{~h}$ or $0 \mathrm{~h}$ respectively. Each value was expressed as the mea $\mathrm{n}$ \pm standard deviation. ** $\mathbf{p}<0.01$, vs untreated cells by myostatin (bar 1); \#\# $\mathbf{p}<0.01$, vs untreated cells by myostatin (bar 4).

that during the process of myostatin-induced HeLa cells apoptosis expression level of endogenous bFGF gene may be suppressed by the exogenous myostatin protein. In the present study, recombinant human myostatin protein was added to culture medium to stimulate HeLa cells. Following treatment with several doses of the fusion protein, detection of mRNA level or protein level of endogenous bFGF gene in HeLa cells was made at the treatment time of $30 \mathrm{~min}$ or $6 \mathrm{~h}$, respectively, with quantitative RT-PCR or ELISA. Results (Figs 1 and 2) showed that myostatin obviously downregulated both mRNA level in HeLa cells $(\mathrm{p}<0.01)$ and pro- tein content of bFGF, secreted by the tumor cells into supertanant $(\mathrm{p}<0.01)$ at the two scheduled time points. Meanwhile, it was found that the inhibition effects were in a dose-dependent manner and the minimum dose $(50 \mathrm{ng} / \mathrm{ml})$ given in this experiment significantly suppressed the expression of endogenous bFGF gene in the cells $(\mathrm{p}<0.01)$, which suggested that in the later experiment $50 \mathrm{ng} / \mathrm{ml}$ fusion myostatin protein would be sure to be effective.

To enquire time effects of myostatin on expression of bFGF gene, we monitored bFGF levels of mRNA in cells and protein in supernatant secreted by HeLa cells stimulated with $50 \mathrm{ng} / \mathrm{ml}$ fusion myostatin. Figures 2 and 3 showed us although both mRNA and protein of bFGF were predominantly detected in the experiment, the obvious changes happened at different time point. During the scheduled treatment time, mRNA content was significantly downregulated from $1 \mathrm{~h}$ to the finished time $(\mathrm{p}<0.01)$, whereas serious downregulation $(p<0.05$ or $p<0.01)$ of protein content of bFGF in culture medium was three hours later than that of mRNA.

Anyway, the results provided evidence that exogenous myostatin inhibited expression of endogenous bFGF gene in HeLa cells, the accurate molecular mechanism and whether the regulatory mechanism participated in the apoptosis process of HeLa cells induced by myostatin would be unveiled in following research work.

\section{Discussion}

Large numbers of background researches have revealed that $\mathrm{bFGF}$ is a tumorigenic factor worth concern, and not only stimulates cells proliferation and angiogenesis in tumor, but also plays vital roles in tumor growth, metastasis as well as prognosis. Thus, it has been chosen as a target molecule for treatment of cancers by some concerned scientists. Some bioremediation approaches aimed at bFGF have been confirmed to be effective to suppress the proliferation of tumor cells, such as antibodies against bFGF $(3,4)$, antisense bFGF gene $(6,15)$, RNase-1 conjugated to bFGF (16), inhibitor of bFGF-induced signal pathway (17-21), mimic
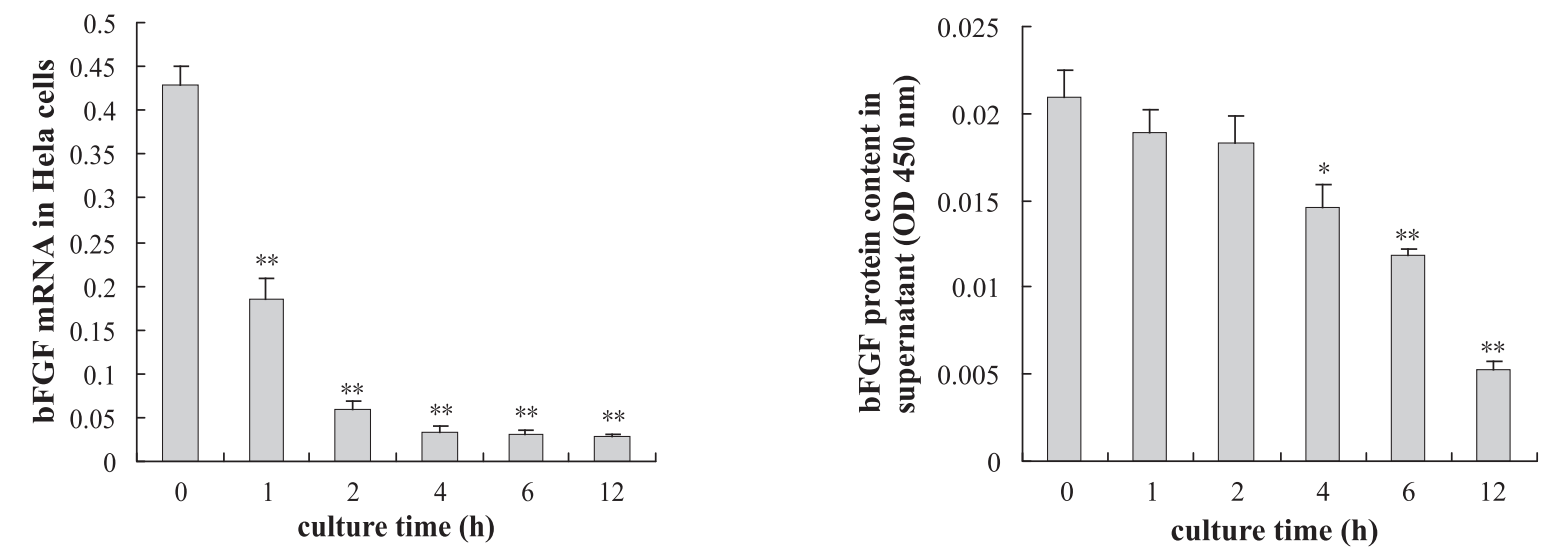

Fig. 3. Effects of myostatin on mRNA (left) and protein (right) levels of bFGF in HeLa cells at indicated time. The cultured Hela cells grown in DMEM with $0.5 \%$ FBS were treated by recombinant human myostatin at dose of $50 \mathrm{ng} / \mathrm{ml}$ for $0,1,2,4,6$ and 12 hours respectively. The treated cells were employed to extract total RNA contributing to detecting mRNA level of bFGF with real-time RT-PCR, and the supernatant was used to detect bFGF protein content with ELISA. Each value was expressed as the mean \pm standard deviation. * $\mathbf{p}<0.05$ or $* * \mathbf{p}<0.01$, vs untreated cells by myostatin. 
peptide to bFGF $(22)$ and other cytokines $(23,24)$. As a negative regulative cytokine of skeletal muscle development and regeneration, myostatin is always confined to skeletal muscle in many studies for a long time. But recently, a novel study described that the cytokine could inhibit proliferation of some tumor cells other than skeletal muscle-derived tumor, such as cervical cancer HeLa cells and human lung adenocarcinoma A549 cells. The study also showed that myostatin-induced cell death was apoptosis and the programmed cell death was generated through mitochondrion pathway (12). In addition, we previously reported an inhibition effect of bFGF on myostatin gene expression in murine $\mathrm{C} 2 \mathrm{C} 12$ myoblasts $(13,14)$.

From the above findings, we easily suppose that during the process of myostatin-induced tumor cell apoptosis, it's on the cards that myostatin downregulates expression of endogenous bFGF gene in tumor cells. It has been reported that bFGF contains four high molecular weight protein isoforms (HMW-bFGFs) and one low molecular weight protein form (LMW-bFGF). The HMWbFGFs located in cell nucleus relate possibly to cell growth and apoptosis, while the LMW-bFGF secreted into extracellular matrix is the mainly bioactive form triggering a series of signaling transduction cascades by binding high-affinity cell surface FGF receptors (25). Above mentioned hypothesis was approved by our investigation in this paper. Our results provided evidence that myostatin not only impaired mRNA content of bFGF gene, but also downregulated extracellular bFGF protein secreted by HeLa cells into supernatant.

It is well documented that both bFGF and myostatin exert their opposite biological roles on cell proliferation and differentiation through intricate signal pathways respectively. Although the accurate mechanism is not completely unveiled, the cross-talk between the two cytokine-induced signal pathways is really in existence. For instance, bFGF activates extracellular signal-regulated kinase $1 / 2$ mitogen-activated protein and phosphatidylinositol 3-kinase to regulate cyclin D1 and $\mathrm{p} 27$, which improve cell cycle transition from $\mathrm{G} 1$ to $\mathrm{S}$ phase (26), whereas myostatin induces p300 degradation to silence cyclin D1 expression and then to arrest cell cycle in G1/S phase through the phosphatidylinositol 3-kinase pathway $(8,9)$, so there would be an interactional relationship between the two growth factors. The conjecture was confirmed in our previous studies, which revealed that bFGF suppressed expression of myostatin gene in murine $\mathrm{C} 2 \mathrm{C} 12$ myoblasts and extracellular signalregulated kinase $1 / 2$ signal pathway participated in the regulatory mechanism. In this paper, suppression of myostatin on expression of bFGF gene in HeLa cells has been discovered, but the unknown regulatory mechanism is yet to be worked out. Our results in this paper implied that myostatin may be regarded as an effective cytokine against bFGF to treat certain cancers.

\section{References}

1. Pallares J, Rojo F, Iriarte J, Morote J, Armadans LI, de Torres I. Study of microvessel density and the expression of the angiogenic factors VEGF, bFGF and the receptors Flt-1 and FLK-1 in benign, premalignant and malignant prostate tissues. Histol Histopathol 2006; 21: 857-865.
2. Dhandapani KM, Khan MM, Wad FM, Wakade C, Mahesh VB, Brann DW. Induction of transforming growth factor-betal by basic fibroblast growth factor in rat $\mathrm{C} 6$ glioma cells and astrocytes is mediated by MEK/ERK signaling and AP-1 activation. J Neurosci Res 2007; 85: 1033-1045.

3. Takahashi JA, Fukumoto M, Kozai Y, Ito N, Oda Y, Kikuchi H, Hatanaka M. Inhibition of cell growth and tumorigenesis of human glioblastoma cells by a neutralizing antibody against human basic fibroblast growth factor. FEBS 1991; 288: 65-71.

4. Xiang JJ, Jin YJ, Huang HL, Wang H, Yang HY, Tang Y. Production preparation of human bFGF monoclonal antibodies and their antitumor activities with MabF7 on melanoma cells B16 in vitro. Chin J Cancer Prev Treat 2008; 15: 19-22.

5. Yang JL. Cloning of basic fibroblast growth factor and its influence on the growth of Hela cells and the expression of angiogenin. Northeast Normal University Ph.D Thesis. Changchun, China 2009.

6. McPherron AC, Lawler AM, Lee SJ. Regulation of skeletal muscle mass in mice by a new TGF-beta superfamily member. Nature 1997; 387 : 83-90.

7. Yang W, Chen Y, Zhang Y, Wang XY, Yang N, Zhu DH. Extracellular signal-regulated kinase $1 / 2$ mitogen-activated protein kinase pathway is involved in myostatin-regulated differentiation repression. Cancer Res 2006; 66: 1320-1326.

8. Yang W, Zhang Y, Li YF, Wu ZG, Zhu DH. Myostatin induces cyclin D1 degradation to cause cell cycle arrest through a phosphatidylinositol 3-kinase/AKT/GSK-3 $\beta$ pathway and is antagonized by insulin-like growth factor 1. J Biol Chem 2007; 282: 3799-3808.

9. Ji M, Zhang Q, Ye JW, Wang XY, Yang W, Zhu DH. Myostatin induces p300 degradation to silence cyclin D1 expression through the PI3K/ PTEN/Akt pathway. Cell Signalling 2008; 20: 1452-1458.

10. Ricaud S, Vernus B, Duclos M, Bernardi H, Ritvos O, Carnac G, Bonnieu A. Inhibition of autocrine secretion of myostatin enhances terminal differentiation in human rhabdomyosarcoma cells. Oncogene 2003; 22: 8221-8232.

11. Langley B, Thomas M, McFarlane C, Gilmour S, Sharma M, Kambadur R. Myostatin inhibits rhabdomyosarcoma cell proliferation through an Rb-independent pathway. Oncogene 2004; 23: 524-534.

12. Bian R. Molecular mechanism of myostatin-induced apoptosis of tumor cells. China Union Medical University \& Chinese Academy of Medical Sciences. M.D Thesis. Beijing, China 2006.

13. Liu HZ, Li Q, Yang XY, Liu L, Liu L, An XR, Chen YF. Expression of basic fibroblast growth factor results in the decrease of myostatin mRNA in murine C2C12 myoblasts. Acta Biochim Biophys Sin 2006; 38: 697-703.

14. Liu HZ, An XR, Chen YF, Zhong JP. Roles of extracellular signal-regulated kinase $1 / 2$ on the suppression of myostatin gene expression induced by basic fibroblast growth factor. Acta Biochim Biophys Sin 2008; 40: 943-948.

15. Inoue K, Perrotte P, Wood CG, Slaton JW, Sweeney P, Dinney CPN. Gene therapy of human bladder cancer with adenovirus-mediated antisense basic fibroblast growth factor. Clin. Cancer Res 2000; 6: 4422- 4431.

16. Futami J, Seno M, Ueda M, Tada H, Yamada H. Inhibition of cell growth by a fused protein of human ribonuclease 1 and human basic fibroblast growth factor. Protein Eng 1999; 12: 1013-1019.

17. Aviezer D, Iozzo RV, Noonan DM, Yayon A. Suppression of autocrine and paracrine functions of basic fibroblast growth factor by stable expression of perlecan antisense cDNA. Mol Cell Biol 1997; 17: 1938-1946. 
18. Javson GC, Gallagher JT. Heparin oligosaccharides: inhibitors of the biological activity of bFGF on Caco-2 cells. Br J Cancer 1997; 75: 9-16.

19. Mohammadi M, McMahon G, Sun L, Tang C, Hirth P, Yeh BK, Hubbard SR, Schlessinger J. Structures of the tyrosine kinase domain of fibroblast growth factor receptor in complex with inhibitors. Science 1997; 276: 955-960.

20. Wagner M, Lopez ME, Cahn M, Korc M. Suppression of fibroblast growth factor receptor signaling inhibits pancreatic cancer growth in vitro and in vivo. Gastroenterology 1998; 114: 798-807.

21. Davol PA, Garza S, Frackelton AR Jr. Combining suramin and a chimeric toxin directed to basic fibroblast growth factor receptors increases therapeutic efficacy against human melanoma in an animal model. Cancer 1999; 86: 1733-1741.

22. McConnell SJ, Thon VJ, Spinella DG. Isolation of fibroblast growth factor receptor binding sequences using evolved phage display libraries. Comb Chem High Throughput Screen 1999; 2: 155-163.
23. Dinney CP, Bielenberg DR, Perrotte P, Reich R, Eve BY, Bucana CD, Fidler IJ. Inhibition of basic fibroblast growth factor expression, angiogenesis, and growth of human bladder carcinoma in mice by systemic interferon-alpha administration. Cancer Res 1998; 58: 808-814.

24. Kaban LB, Mulliken JB, Ezekowitz RA, Ebb D, Smith PS, Folkman J. Antiangiogenic therapy of a recurrent giant cell tumor of the mandible with interferon alfa-2a. Pediatrics 1999; 103: 1145-1149.

25. Malkowski A, Sobolewski K, Jaworski S, Bankowski E. FGF binding by extracellular matrix components of Wharton's jelly. Acta Biochim Pol 2007; 54: 357-363.

26. Zhu YL. The signal mechanism underlying basic fibroblast growth factor-mediated cell proliferation in hepatic cancer Bel-7402 cells. China Medical Unviersity Ph.D Thesis. Shenyang, China 2009.

Received September 16, 2011. Accepted September 21, 2011. 